\title{
The Effect of Calcium Carbonate on the Stability of Acid Treated Papers
}

\author{
E.L. Graminski* and E.J. Parks** \\ National Bureau of Standards, Washington, DC 20234
}

December 17, 1980

\begin{abstract}
Exposure of kraft wood pulps to an acidic medium results in a destabilization of wood pulp. The degree of destabilization appears to depend on the concentration of acid the pulp is exposed to. The addition of calcium carbonate to acid destabilized pulp does not restore the pulp to its original stability. The absorption of alkali metals is $\mathrm{pH}$ dependent which could explain the destabilization of wood pulps when exposed to an acid medium. A number of questions arise about the merit of stabilizing degraded paper documents by deacidification with alkaline earth salts and the usefulness of an alkaline reserve in paper.
\end{abstract}

Key words: Alkaline reserve; cellulose stabilizers; paper deacidification; paper destabilization; paper perma. nence; $\mathrm{pH}$ history

\section{Introduction}

Concern over the instability of paper has continued for more than 100 years. In a book published in 1824, the author lamented over the condition of paper in books that were less than 10 years old. [1] ${ }^{1}$ If that were noted today, it would most likely be assumed that the manufacture of paper from wood pulp was to blame. In 1824, it was the formidable rag paper that proved to be unstable. Nevertheless, paper can be made to last for centuries or millenia. In evidence is the fact that many books, centuries old, are still in excellent condition.

The stabilization of paper is a matter of enormous worldwide economic and cultural impact, and efforts have been made for at least fifty years on the one hand to determine causes of paper instability and on the other to evaluate the longevity of paper by means of accelerated aging. The earliest experiments in accelerated aging involved placing paper in an oven at 100 to $105^{\circ} \mathrm{C}$ for times ranging from 20 to $125 \mathrm{~h}[2,3]$. The classification of paper permanence was based on the retention of the original properties of unaged paper. If a paper subjected to accelerated aging manifested a high retention of physical properties, it was considered permanent, while papers that manifested considerable decline in properties were considered to be impermanent.

\footnotetext{
"Current address: 201-3A, Bureau of Engraving and Printing, 14th \& C St SW, Washington, DC 20228

- Center for Materials Science, National Measurement Leboratory

'Figures in brackets indicate literature references at the end of this paper.
}

No attempts were made to predict the "natural" lifetime of paper, and until recently, data were not available for meaningful comparisons of accelerated and long-term aging, necessary to evaluate the former.

The accelerated aging studies did indicate that exposure of pulp to excessive acidity resulted in an unstable manufactured product [4]. The origin of most of the acid was aluminum sulfate, which was used to size paper with rosin. Aluminum sulfate hydrolyzes in water to produce sulfuric acid. A later study showed that the aluminum ion was selectively retained by pulp fibers [5]. More recently, Parks [6] inferred, on the basis of thermoanalytic data, that the aluminum ion, interacting with carboxyl groups in cellulose, might be a contributing cause for the instability of paper. Parks et al [7, 8, 9] showed that large amounts of organic acid were generated during the humid accelerated aging of unstable, weakly acidic paper, and that the amounts of acid generated were correlated with changes in physical properties and color reversion. Their data did not indicate catalysis of aging by the generated acid.

Prior accelerated aging tests had demonstrated that paper filled with calcium carbonate possessed considerable stability [10]. An investigation of naturally aged paper produced further evidence for the stabilizing effect of calcium carbonate [11], supporting the rationalization that initially acid papers were unstable because of acid hydrolysis and that alkaline papers, conversely, are stable. It was further reasoned that treatment of degraded, acidic paper documents with calcium alkali would neutralize acidity and arrest further acid-catalyzed degradation [12]. 
With one exception [11], all of the information on the relationship of paper stability and alkalinity was derived from an accelerated aging test that consisted of placing paper specimens in an oven at $100^{\circ} \mathrm{C}$ for 72 hours [13]. The validity of accelerated aging at a single temperature itself is questionable because of demonstrated differences in the temperature dependence of the degradation rate constants for different papers [14]. Furthermore, Graminski et al [15] recently have shown that the deterioration rate of properties closely related to the tensile strength of paper is directly proportional, in an accelerated aging test at a given temperature, to the moisture content of the paper. When one considers the low relative humidity of the atmosphere in an oven at $100^{\circ} \mathrm{C}$, even when the relative humidity of the surrounding environment is high, it is easy to infer that little fiber degradation occurs under these circumstances, and that oven aging must be fundamentally incomparable with natural aging.

As an added source of confusion, however, many workers have observed appreciable declines in folding endurance and internal tearing resistance during oven aging. Functional groups, introduced during pulp manufacturing and especially during bleaching, react to form cross-links. As the number of cross-links increases, wet strength increases and fiber flexibility decreases. The decreased fiber flexibility results in decreases in folding endurance [8].

Unless paper contains an adequate amount of water, it must be assumed that the three main degradative reactions - cross-linking, hydrolysis, and oxidation [7, 8, 9]—can occur in different ratios than in natural degradation. Thus, the assessment of "real" permanence would lack a valid theoretical correlation with dry aging at a high temperature.

Wilson and Parks [16] recently compared the changes in 18 papers after three days of oven aging at $100{ }^{\circ} \mathrm{C}$ with changes observed after 36 years of natural aging in an office in which the relative humidity varied over the years. Considering all 18 papers as a group, the correlation between accelerated aging under these conditions and uncontrolled "natural" aging was not high. Comparisons between various subsets generated higher correlations, but the decline of physical properties in some papers was lower after 36 years of natural aging than after three days of oven aging, while the reverse was true for other papers.

However, their data indicate an interesting correlation between head box $\mathrm{pH}$ and retention of folding endurance after natural aging: the higher the head box $\mathrm{pH}$, the greater the retention of folding endurance. The coefficient of correlation between the head box $\mathrm{pH}$ and retention of folding endurance for two sets of acid wood pulp papers was 0.92 and 0.99 . The coefficient of correlation for one set of rag papers was somewhat lower at 0.86 . In addition, their data show an excellent correlation between head box $\mathrm{pH}$ and the wet strength of the paper, observed after 36 years of natural aging and expressed as a percent of dry strength. The coefficient of correlation for each of the two sets of acid wood pulp papers was 0.99 and for the rag papers it was 0.97. These data suggest the previously unevaluated hypothesis that the $\mathrm{pH}$ "history" of a pulp affects the permanence of paper made from it.

In the present investigation, aging was conducted to determine whether the addition of calcium carbonate would impart resistance to humid aging, to paper previously subjected to acid extraction. Pulps were treated with dilute mineral acid and aluminum sulfate to impart instability. Subsequent treatment with calcium carbonate produced alkaline handsheets. The handsheets were subjected to accelerated aging at $90^{\circ} \mathrm{C}$ and 50 percent $R$. H., in order to indicate whether the addition of the alkaline salt, calcium carbonate, to a destabilized pulp result in a paper fully stabilized against aging under humid conditions.

\section{Experimental Procedure}

\subsection{Samples}

Handsheets were prepared from a northeastern bleached kraft pulp containing approximately 85 percent alpha cellulose and 15 percent hemicellulose. Handsheets which were prepared from the pulp as received (untreated) were made in tap water. All other handsheets were prepared in distilled water (table 1). The handsheets were stored in a chamber controlled at $35^{\circ} \mathrm{C}$ and 90 percent relative humidity for at least $18 \mathrm{~h}$ to relieve any stresses which may have formed during the preparative stages.

The "deashed" handsheets were made from demineralized pulp. Pulp was torn into pieces approximately two square inches and soaked in $0.1 \mathrm{~N}$ hydrochloric acid at a five percent consistency. After one hour, the acid was drained and fresh acid was added to the pulp. After the fourth acid treatment, the pulp was washed with distilled water on a large Buchner funnel until the $\mathrm{pH}$ of the filtrate was identical to the $\mathrm{pH}$ of the distilled water and remained at that $\mathrm{pH}$ for an additional three to four rinses.

Aluminum treated handsheets were prepared from the deashed pulp after treatment with $0.1 \mathrm{M}$ calcium acetate. Following four one-half hour treatments with $0.01 \mathrm{M}$ aluminum sulfate, the treated pulp was washed extensively.

Beating of pulps was done in a laboratory mill at 10 percent consistency with no clearance between bedplate and roll for 4,000 revolutions at $3.33 \mathrm{~N}$ (.34 kg force) and a relative velocity of roll to bedplate of $6 \mathrm{~m} / \mathrm{sec}$. With the exception of the untreated pulp, beating was done in distilled water using sufficient wet pulp to provide $40 \mathrm{~g}$ of the dry pulp for each charge. If several charges were used, they were placed in a large stainless steel container, diluted to 
approximately one percent consistency and blended for approximately one hour prior to preparing handsheets.

Aliquots, containing sufficient pulp to make a $30.5 \times 30.5$ $\mathrm{cm}$ handsheet having a weight of $70 \mathrm{~g} / \mathrm{m}^{2} \pm 5$ percent, were placed in a British Disintegrator (see TAPPI Standard T205os-71), diluted with distilled water to a consistency of approximately 0.5 percent and disintegrated for 3,000 revolutions. The disintegrated pulp was placed in a $30.5 \mathrm{x}$ $30.5 \mathrm{~cm}$ deckle box containing approximately $28 \mathrm{~L}$ of distilled water. The contents were agitated by moving a perforated plate up and down five times, followed by a pause of approximately 10 seconds, then drained through a 100 mesh monel wire screen. The wire containing the formed sheet was placed on a blotter, covered with wool felt and consolidated by pressing with a $33 \mathrm{~cm}$ long roller weighing $22.5 \mathrm{~kg}$. The sheet was carefully removed from the wire, placed between wool felts and passed through a roll press at a pressure of approximately $7 \mathrm{~kg} /$ linear $\mathrm{cm}$. The pressed sheet was then dried on a drum dryer at $95^{\circ} \mathrm{C}$ for approximately four minutes. The tension on the endless felt of the drum dryer was adjusted to restrict shrinkage to a minimum. The sheets were stress relieved by suspending them in a humidity chamber at $35{ }^{\circ} \mathrm{C}$ and 90 percent relative humidity for approximately 16 hours.

If the handsheets were to be filled with calcium carbonate, $0.65 \mathrm{~g} \mathrm{CaCO}_{3}$ was added to the distilled water in the deckle box and dispersed. Disintegrated pulp was then added, stirred and allowed to equilibrate for one minute before the water was drained. The remainder of the handsheet preparation procedure was as described above.

A number of handsheets also were prepared from aluminum sulfate treated pulp which was in contact with the $\mathrm{CaCO}_{3}$ for one hour before forming into a handsheet. The purpose of this procedure was to determine whether the contact time with the $\mathrm{CaCO}_{3}$ affected the stabilization of paper.

\subsection{Accelerated Aging}

Constant temperature oil baths were constructed of stainless steel. An immersion heater controlled by a relay box and thermoregulator provided the principal source of heat with a desired temperature control to $\pm 0.1^{\circ} \mathrm{C}$. A heating coil immersed in the bath, was an auxiliary source of heat, with current input controlled by a variable transformer. The oil was continuously pumped in the bath with an immersion type pump to ensure uniform temperature distribution.

Two baths in series, maintained at $75^{\circ} \mathrm{C}$ and $90^{\circ} \mathrm{C}$, were equipped with prehumidifiers and aging vessels, respectively. To provide a vented atmosphere of 50 percent relative humidity in the aging vessels, about $50 \mathrm{~cm}$ of gas per minute was metered through water and saturated in the prehumidifier at $73{ }^{\circ} \mathrm{C}$, passed through glass tubing sur- rounded by a heating jacket at a temperature somewhat higher than $73{ }^{\circ} \mathrm{C}$ to avoid condensation, then through coiled glass tubing immersed in the second bath at $90^{\circ} \mathrm{C}$, and finally through the aging vessel containing suspended paper specimens. The baths were covered with black cloth to exclude light.

Humid air at 50 percent relative humidity and $90^{\circ} \mathrm{C}$ contains about 14 percent oxygen gas, 30 percent moisture and 56 percent nitrogen gas. In order to obtain a humid atmosphere containing about 20 percent oxygen gas, a mixture of 30 percent oxygen gas and 70 percent nitrogen was substituted for air and was saturated at $73^{\circ} \mathrm{C}$. According to calculations based on published tables, this gas contained about 20 percent oxygen.

Aging periods of $1,3,6,12$, and 24 days were selected to provide information at various degress of degradation. In some cases the one day period or the three day period was omitted.

\subsection{Properties Investigated}

The following properties were investigated, using the listed TAPPI test methods: Folding Endurance T511 Sn.69, Brightness T452 OS-58, Alkaline Solubility T212 OS-54, Copper number T430 M-52, Tensile Strength T494 OS-70 using $1.5 \mathrm{~cm}$ wide specimens at a span of $10 \mathrm{~cm}$ and a rate of elongation of $1 \mathrm{~cm} / \mathrm{min}$., and $p H$ by method T509 SU-68 with the exception that the $\mathrm{pH}$ measurement was made on the decantate.

Internal tear was performed on an Elmendorf tear tester having a $200 \mathrm{~g}$ capacity. A single ply was used unless the tear strength deteriorated considerably, necessitating three or four plies in order to obtain a reading in the range sug. gested for the instrument.

Zero span tensile strength was determined with the aid of specially designed commercial zero span clamps which were attached to a commercial constant rate of elongation tensile tester. The rate of elongation was $0.3 \mathrm{~mm} /$ minute.

Wet tensile strength was determined on a constant rate of elongation tensile tester using specimens $1.5 \mathrm{~cm}$ wide and $10 \mathrm{~cm}$ long. The samples were soaked for two hours in distilled water prior to testing.

Moisture regain specimens were first conditioned in a desiccator for 24 hours and then exposed to an atmosphere maintained at $23 \pm 1{ }^{\circ} \mathrm{C}$ and $50.0 \pm 2.0$ percent relative humidity for at least 24 hours. Specimens of approximately two grams were placed in weighing bottles and the total weight was determined to the nearest $0.1 \mathrm{mg}$. The sample was then dried in a vacuum oven at $105^{\circ} \mathrm{C}$ for one hour, covered immediately upon opening the oven, cooled in a desiccator for two hours, and reweighed. This procedure was repeated until changes in weight were no longer observed. The specimen was then removed from the weighing bottle, and the empty bottle was dried in the vacuum oven 
at $105^{\circ} \mathrm{C}$ for one hour, cooled in a desiccator for two hours and weighed. The difference between the weight of the bottle containing the dried specimen, and the empty weighing bottle was the weight of the anhydrous. specimen. The weight of water divided by anhydrous specimen multiplied by 100 was the percent moisture regain.

Aluminum was determined in ash by the p-hydroxyquinoline complexation method (17). Calcium in ash was titrated in reacted solution with EDTA, using cal-red indicator (18).

The results for folding endurance and zero span tensile strength are given in tables 2 and 3 and represent the averages for 8 to 12 specimens. The results of these two properties are representative of all the other properties investigated. The results for the remaining properties are not given.

\section{Discussion}

Two factors, critical in accelerated aging studies of paper, are not considered in the present investigation: (l) the temperature dependence of degradation rate constants, and (2) effects of moisture on degradation rates. Since the accelerated aging conditions were identical, and closely controlled, and since each set of handsheets was prepared from a single batch of pulp, the effect of treatments on the pulp stability under these controlled conditions can be readily assessed.

The untreated pulp (table 1) was comparatively stable during humid accelerated aging tests over the time spans indicated. Minimal decline in the zero span tensile strength indicates that fibers did not experience serious degradation (table 2). Relatively slow increases in wet strength (table 3) and decreases in folding endurance (table 4) further differentiate this paper from the less stable modifications.

Demineralization with dilute acid resulted in a remarkable decrease in stability. The wet strength of deashed paper increased rapidly during the early stages of humid aging (table 3 and figure 1 ), reached a maximum and then rapidly declined over the remaining aging interval. Treatment of the deashed pulp with aluminum sulfate resulted in little or no additional effect on the degradation rate (tables 2-4 and figure 2). These data do not support Parks' inference (6) that aluminum destabilized paper, as the aluminum treated paper is not less stable than the deashed paper from which it was prepared.

The addition of calcium carbonate to either the deashed or aluminum-treated paper appears to retard the deterioration process. The increase in wet strength is much slower at the onset of aging. In fact, the changes in wet strength with time initially are only slightly different from those of the untreated paper. $\mathrm{CaCO}_{3}$-filled paper reaches a maximum and then, unlike untreated paper, declines over the remaining interval of aging. The rate of decline of zero span tensile strength and that of folding endurance decreased also when calcium carbonate was added to either deashed or aluminum-treated pulp, but the rate of deterioration still was

TABLE 1. Description of Samples

\begin{tabular}{|c|c|c|c|c|c|c|c|}
\hline Pulp Treatment & $\begin{array}{c}\text { Mass Per } \\
\text { Unit Area } \\
\left(\mathrm{g} / \mathrm{m}^{2}\right)\end{array}$ & $\begin{array}{l}\text { Thickness } \\
\text { (mm) }\end{array}$ & $\begin{array}{r}\mathrm{p} \\
\text { Cold }\end{array}$ & Hot & $\begin{array}{c}\text { Ash } \\
\text { Content } \\
(\%)\end{array}$ & $\begin{array}{l}\text { Aluminum } \\
\text { Content } \\
\text { (meq/100g) }\end{array}$ & $\begin{array}{c}\text { Calcium } \\
\text { Content } \\
\text { (meq/100g) }\end{array}$ \\
\hline None & 78 & .134 & 6.18 & 6.17 & 0.112 & - & 2.5 \\
\hline Deashed & 75 & .138 & 4.93 & 5.04 & 0.006 & - & - \\
\hline Deashed $+\mathrm{CaCO}_{3}$ & 78 & .145 & 7.98 & 8.70 & - & - & 62 \\
\hline Aluminum Treated & 68 & .145 & 5.22 & 4.68 & 0.141 & 3.12 & - \\
\hline Aluminum Treated $+\mathrm{CaCO}_{3}(1$ minute $)$ & 70 & .150 & 7.80 & 8.80 & - & 3.35 & 67 \\
\hline Aluminum Treated $+\mathrm{CaCO}_{3}$ (1 hour) & 73 & .142 & 7.88 & 8.52 & - & 1.5 & 33 \\
\hline
\end{tabular}

TABLE 2. Effect of Aging at $90^{\circ} \mathrm{C}$ and 50 Percent Relative Humidity on Folding Endurance (Double Folds Under $1 \mathrm{~kg}$ of Tension)

\begin{tabular}{|c|c|c|c|c|c|c|}
\hline \multirow{3}{*}{ Pulp Treatment } & \multicolumn{6}{|c|}{ Aging Time, Days } \\
\hline & 0 & 1 & 3 & 6 & 12 & 24 \\
\hline & \multicolumn{6}{|c|}{ Double Folds } \\
\hline None & 1890 & 1800 & - & 1610 & 1510 & 500 \\
\hline Deashed & 1390 & 970 & 830 & 21 & 0 & 0 \\
\hline Deashed $+\mathrm{CaCO}_{3}$ & 1460 & 1080 & 870 & 430 & 11 & 0 \\
\hline Aluminum Treated & 960 & - & 52 & 2 & 0 & 0 \\
\hline $\begin{array}{l}\text { Aluminum Treated }+\mathrm{CaCO}_{3} \\
\text { (I minute) }\end{array}$ & 970 & - & 623 & 410 & 61 & $\mathbf{0}$ \\
\hline $\begin{array}{l}\text { Aluminum Treated }+\mathrm{CaCO}_{3} \\
\text { (1 hour) }\end{array}$ & 1330 & - & 728 & 326 & 5 & 0 \\
\hline
\end{tabular}


much greater than observed in paper made from untreated pulp (tables 2 and 4). Increasing the contact time of the calcium carbonate with the aluminum-treated pulp did not appear to influence the degradation rate, even though onehalf of the aluminum was displaced (table 1 ).

The results of this investigation suggest that destabilization occurs when pulps come into contact with an acid medium. Since treatment of deashed pulp with calcium carbonate does not restore the pulp to its original stability, it is evident that neither the presence of calcium nor the alkalinity of calcium carbonate is sufficient to ensure stabilization of the acid-modified pulp.

Since alkaline papers are frequently stable, however, we suggest that the $\mathrm{pH}$ history of a pulp, particularly whether or not the pulp is exposed to acid media at critical points in the paper making process, is more important to permanence than the final $\mathrm{pH}$ of the paper. This hypothesis would be consistent with either modification of the unaged pulp by acid treatment, or extraction of a substance under acid conditions-e.g., trace metals-that is capable of effecting stabilization. Restoration of stability then would occur only if the effect of acid extraction could be reversed, e.g., by returning the same trace metals to the fibers.

In view of the limited improvement conferred by calcium carbonate to pulp destabilized by contact with acid, possi- ble side reactions that may result from deacidification of deteriorated documents assume greater importance. The purpose in treating degraded, acid paper is to neutralize the acid and arrest further degradation due to acid hydrolysis. However, alkaline hydrolysis under these conditions is a disturbing possiblity.

During natural degradation, paper undergoes oxidation to some extent. Cellulose oxidized with formation of one or more alkoxy groups at the 1-, 3-, or 6-position of the anhydroglucose ring. In alkaline media, the possibility arizes of rapid elimination of an alkoxyl group, resulting in chain scission with the formation of one reducing and one nonreducing end group [19]. The reducing group would further oxidize to carboxylic acid. Therefore an old document, after extensive oxidation, could actually suffer alkali-catalyzed degradation during the deacidification process, this risk increasing with the strength of the alkalinity of the medium.

\section{Conclusion}

Extraction of pulp with mineral acid (deashing) severely reduces the resistance of paper manufactured from such pulp to accelerated aging under humid conditions. Addition of aluminum ion does not further diminish the stability of deashed pulp. Addition of calcium carbonate to acid-

TABle 3. Effect of Aging at $90^{\circ} \mathrm{C}$ and 50 Percent Relative Humidity on Zero Span Tensile Strength, Expressed as Km of Paper

\begin{tabular}{|c|c|c|c|c|c|c|}
\hline \multirow{3}{*}{ Pulp Treatment } & \multicolumn{6}{|c|}{ Aging Time, Days } \\
\hline & 0 & 1 & 3 & 6 & 12 & 24 \\
\hline & \multicolumn{6}{|c|}{ Breaking Length, $\mathrm{Km}$} \\
\hline None & 14.7 & 14.9 & - & 14.8 & 14.2 & 12.1 \\
\hline Deashed & 14.2 & 12.9 & 10.4 & 7.7 & 3.8 & 0.9 \\
\hline Deashed $+\mathrm{CaCO}_{3}$ & 13.3 & 13.0 & 13.0 & 12.2 & 9.0 & 3.4 \\
\hline Aluminum Treated & 12.9 & - & 10.0 & 6.3 & 3.8 & 1.1 \\
\hline $\begin{array}{l}\text { Aluminum Treated }+\mathrm{CaCO}_{3} \\
\text { (1 minute) }\end{array}$ & 13.0 & - & 12.7 & 12.3 & 10.4 & 5.9 \\
\hline $\begin{array}{l}\text { Aluminum Treated }+\mathrm{CaCO}_{3} \\
\text { (1 hour) }\end{array}$ & 13.0 & - & 12.5 & 11.3 & 8.1 & 2.0 \\
\hline
\end{tabular}

TABle 4. The Degradation Rates for Zero Span Tensile Strength and Folding Endurance of Various Papers at $90^{\circ} \mathrm{C}$ and 50 Percent Relative Humidity

\begin{tabular}{|c|c|c|}
\hline Pulp Treatment & $\frac{\Delta[\log \text { Z.S.T. }]}{\Delta \mathrm{T} \text { (days) }} \times 10^{\mathrm{s}}$ & $\frac{\Delta[\log \text { Fold }]}{\Delta \mathrm{T}, \text { days }} \times 10^{3}$ \\
\hline None & 4 & 23 \\
\hline Deashed & 51 & 298 \\
\hline Deashed $+\mathrm{CaCO}_{3}$ & 25 & 174 \\
\hline Aluminum Sulfate Treated & 44 & 447 \\
\hline $\begin{array}{l}\text { Aluminum Sulfate Treated }+ \\
\mathrm{CaCO}_{3}(1 \text { minute })\end{array}$ & 15 & 123 \\
\hline $\begin{array}{l}\text { Aluminum Treated }+\mathrm{CaCO}_{3} \\
\text { (1 hour) }\end{array}$ & 23 & 206 \\
\hline
\end{tabular}




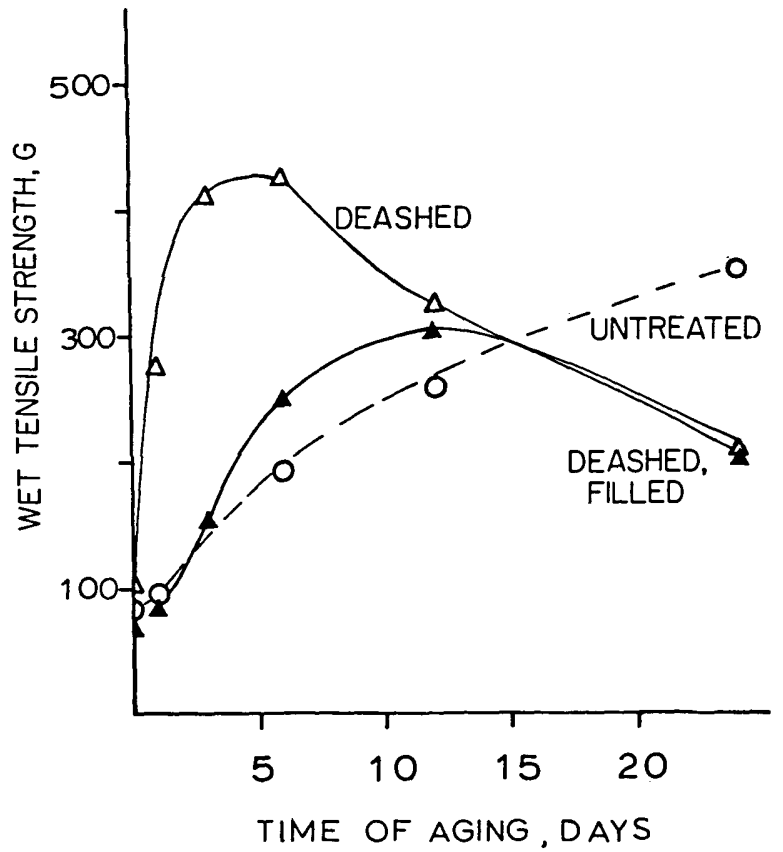

FIGURE 1. Generation of wet strength in untreated, deashed, and $\mathrm{CaCO}_{3}$ filled deashed paper as a function of time at $90^{\circ} \mathrm{C}$ and 50 percent relative humidity.

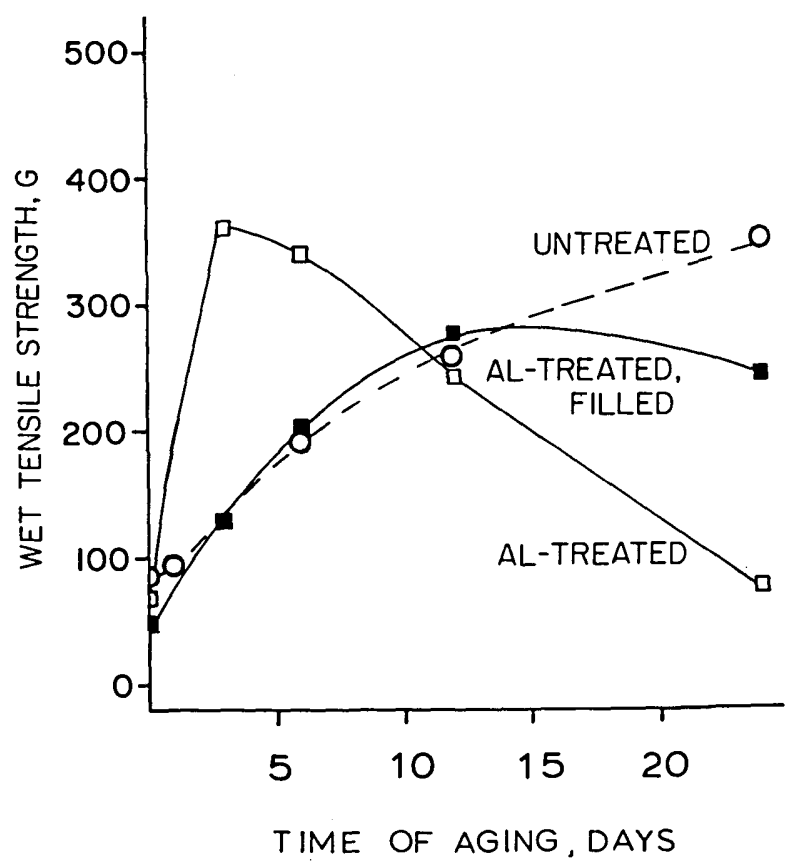

FIGURE 2. Generation of wet strength in untreated-, Al-treated, and $\mathrm{CaCO}_{3}$-filled Al-treated paper as a function of time at $90^{\circ} \mathrm{C}$ and 50 percent relative humidity.

TABLE 5. Effect of Aging at $90^{\circ} \mathrm{C}$ and 50 Percent Relative Humidity on Wet Tensile Strength, Grams

\begin{tabular}{|c|c|c|c|c|c|c|}
\hline \multirow{3}{*}{ Pulp Treatment } & \multicolumn{6}{|c|}{ Aging Time, Days } \\
\hline & 0 & 1 & 3 & 6 & 12 & 24 \\
\hline & \multicolumn{6}{|c|}{ Wet Tensile Strength, Grams } \\
\hline None & 82 & 95 & - & 191 & 258 & 350 \\
\hline Deashed & 104 & 277 & 415 & 427 & 323 & 206 \\
\hline Deashed $+\mathrm{CaCO}_{3}$ & 67 & 83 & 154 & 249 & 301 & 205 \\
\hline Aluminum Treated & 81 & - & 362 & 340 & 241 & 97 \\
\hline Aluminum Treated $+\mathrm{CaCO}_{3}$ & 43 & - & 30 & 203 & 277 & 242 \\
\hline
\end{tabular}

deashed pulp causes the paper to be alkaline and only partially restores the resistance to aging that is lost on acid extraction.

Consideration of data found in the literature, in conjunction with the current data, suggest the hypothesis that paper is rendered unstable by acid extraction of undetermined stabilizers, and that stability is not fully restored merely by adding an alkaline salt to the pulp. Hence the $\mathrm{pH}$ history of the pulp, particularly whether it is exposed to acid during manufacture acquires great importance.

The practice of deacidifying old documents with alkaline salts needs to be considered in the light of possible damage to such documents by hydrolytic cleavage of $\beta$-alkoxyl groups, catalyzed by alkaline media.

\section{References}

[1] Murray, John. Observations and experiments on the bad composition of modern paper, with the desorption of a permanent writing ink which cannot be discharged. London: G. and W. B. Whitaker, 1824.

[2] Hall, G. Permanence of paper. Paper Trade Journal 82 (14): 185-191; 1926 April.

[3] Rasch, R. H. A study of purified wood fibers as a papermaking material. J. Res. Nat. Bur. Stand. (U.S.). 3: 469-506. 1929 February. 
[4] Rasch, R. H.; Shaw, M. B.; Bicking, G. W. Highly purified wood fibers as papermaking materials. J. Res. Nat. Bur. Stand. (U.S.). 7: 765-782; 1931 August.

[5] Launer, H.F. Retention of aluminum ion and hydrogen ions in papers. J. Res. Nat. Bur. Stand. (U.S.). 23: 663-674; 1939 December.

[6] Parks, E. J. Thermal analysis of modified cellulose. Tappi 54 (4): 537-544; 1971 April.

[7] Parks, E.J., Hebert, R. L. Accelerated aging of laboratory handsheets: changes in acidity, fiber strength, and wet strength NBS Report 10627, NTIS Com 75 10164; 1971 December. 42 p.

[8] Parks, E.J.; Hebert, R.L. Accelerated aging of laboratory handsheets: retention of folding endurance, internal tear, bursting strength, and tensile strength. NBS Report 10628. NTIS Com 75 10165; 1971 December. 68 p.

[9] Parks, E.J.; Hebert, R. L. Accelerated aging of laboratory handsheets: reflectance, moisture regain, sonic modulus, and differential thremal analysis. NBS Report 10687. NTIS Com 75 10162; 1972 February. $30 \mathrm{p}$.

[10] Shaw, M. B.; O'Leary, M. J. Effect of filling and sizing materials on stability of book papers. J. Res. Nat. Bur. Stand. (U.S.). 21 : 671-695; 1938 November.

[11] Hanson, F. S. Resistance of paper to natural aging. Paper World 20: $1157-1163 ; 1939$.
[12] Barrow, W.J. Deterioration of book stock, causes and remedies. Richmond, Virginia: Virginia State Library Publications; 1959.70 p.

[13] TAPPI testing methods and recommeded practices. Effect of heating on folding endurance (Relative Stability of Paper). Suggested Test Method T 453 su-70. New York: Technical Association of the Pulp and Paper Industry; 1976.

[14] Gray, G. G. An accelerated aging study comparing kinetic rates vs. TAPPI Standard 453. Tappi 52 (2): 325-334; 1969 February.

[15] Graminski, E. L;; Parks, E. J.; Toth. E. E. The effects of temperature and moisture on the accelerated aging of paper. Eby, R. K., ed. Durability of Macromolecular Materials. Washington, D.C.: American Chemical Society Symposium Series 95; 1979. 342-355.

[16] Wilson, W. K.; Parks, E. J. Comparison of accelerated aging of book papers in 1937 with 36 years of natural aging. NBSIR 74-362. NTIS PB 246-554; 1974 December.

[17] Vogel A. I. A Textbook of Quantitative Inorganic Analysis. New York: John Wiley and Sons; 1961. p 386.

[18] Scandinavian pulp, paper and board testing committee. Calcium in pulp. Svensk Papperstidning 65: $411 ; 1962$.

[19] Isbell, H. S. Interpretation of some reactions in the carbohydrate field in terms of consecutive electron displacement. J. Res. Nat. Bur. Stand. (U.S.). 32: 45-59; 1944 February. 